\title{
Danske erfaringer vedrørende selvmord efter deltagelse i FN's fredsbevarende styrker
}

\author{
Ved Jacob H ansen-Schwartz, G ert Jessen og H ans O le Jørgensen
}

Mange lande har siden Anden Verdenskrig haft tradition for at udsende soldater på fredsbevarende missioner af forskellig karakter. Danmark har i denne periode støttet forskellige FN-missioner, og op gennem 1990'erne har det isaer vaeret det tidligere Jugoslavien, som har vaeret indsatsområde, og der har også vaeret udsendt et betydeligt større antal soldater i disse år end tidligere.

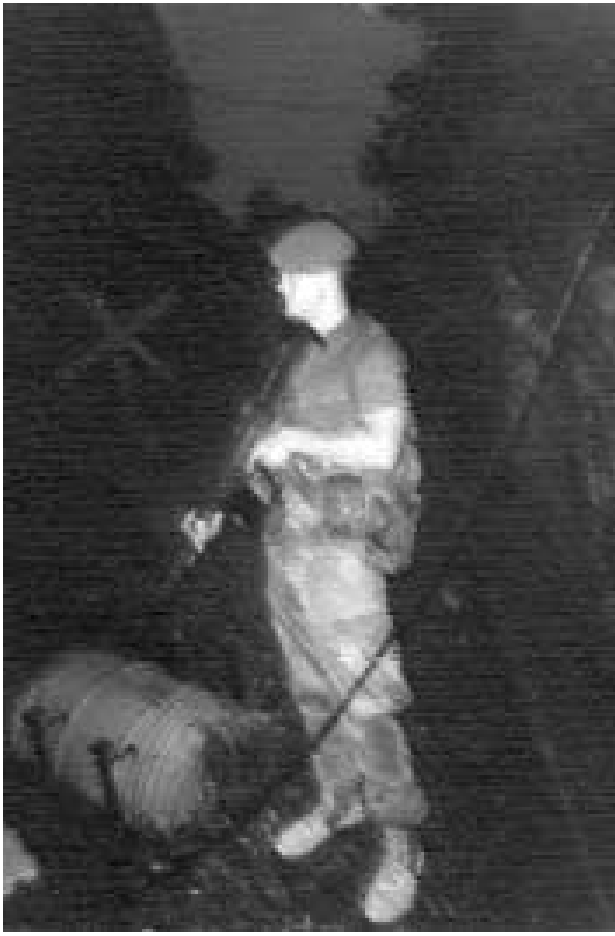

De fredsbevarende missioner i det tidligere Jugoslavien har - også i Danmark tiltrukket sig mediernes bevågenhed. $0 \mathrm{p}$ mærksomheden på de forskellige reaktioner og sygdomme blandt deltagende soldater er steget betydeligt, og især har der været megen opmærksomhed på FN -soldaternes fysiske såvel som psykiske helbred efter de voldsomme begivenheder i K roatien i 1995

Et af de særligt bekymrende områder har været selvmordsadfærden blandt tidligere udsendte danske FN -soldater. En undersøgelse af psykiske efterreaktioner hos udsendt personel foretaget af Psykologisk $A$ fdeling ved Forsvarets $C$ enter for Lederskab viste, at 1,5\% af de adspurgte fra det danske hold 7 og 8 fra FN 's mission i Kroatien i 1995 (U N CR O) "ret ofte" eller "meget ofte" efter hjemsendelse havde haft tanker om selvmord (A ndersen 1998).

Forsvarets Sundhedstjen este tog med baggrund $\mathrm{i}$ en forespørgsel fra Forsvarskommandoen i 1998 initiativ til udførelsen af et videnskabeligt pilotstudie med henblik på nærmere at belyse selvmordsadfærd blandt forsvarets udsendte personel i fredsstøttende operationer. Fokusi pilotstudiet har været at give en tentativ beskrivelse af en mulig overhyppighed af selvmord blandt udsendte.

\section{Metode}

Personidentifikationsnumre fra FN personel-administrationssystemet årgang 1995 til 1997 blev sammenlignet med R egister for Selvmord. I den observerede periode blev i alt 3.859 soldater udsendt til en international mission. A f de udsendte var 2,4\% (91) kvinder. A Idersmæssigt var $62 \%$ mellem 20 og 25 år gamle - den yngste 18 år og den ældste 59 år. Ca. 95\% gjorde tjeneste i eks-Jugoslavien.

For hvert personidentifikationsnummer i FN personel-administrationssystemet kunne udsendelsestidspunkt og tilknyttet enhed (specificeret efter underafdeling) fastslås. I tilfælde af selvmord eller anden voldelig død, blev stamkort rekvireret med henblik på nærmere beskrivelse af personens tjenesteforløb. I tilfælde af at en underafdeling havde to eller flere soldater, som efterfølgende begik selvmord, blev underafdelingen beskrevet med henblik på identifikation af eventuelle disponerende faktorer. Beskrivelsen blev blandt andet foretaget ved opfølgende interview af personellet fra den pågældende underafdeling. Som sammenligningsgrundlag blev incidensen af selvmord i en aldersog kønsmæssig sammenlignelig population anvendt.

\section{Resultater}

I den observerede kohorte fandtes ét dødsfald som følge af en bilulykke og fire mænd i alderen 21 til 24 år havde begået selvmord. I en alders- og kønsmæssig sammenlignelig population ville der i samme periode i en gruppe på 3.859 mennesker statistisk forekomme 3 selvmord, hvilket ikke umiddelbart tyder på en markeret overhyppighed. Der kan argumenteres for, at udsendte FN soldater kunne være en positiv selekteret gruppe, da det fx drejer sig om unge mænd ved overgennemsnitligt godt helbred, hvorfor man måske også kunne forvente et relativt reduceret antal selvmord i denne gruppe. U d af de fire observerede selvmord skete to umiddelbart kort tid før afrejse og to efter udsendelse. A f stamkortoplysninger fremgik det, at de to, som begik selvmord før udsendelse, havde været tjenestegørende gennem et antal år og den ene havde desuden erfaring fra tidligere udsendel se.

De to, som begik selvmord efter hjemsendelse, havde forud for udsendelse aftjent deres værnepligt og havde umiddelbart efterfølgen de tegnet kontrakt med henblik på udsendelse. D et er værd at bemærke, at de to sidstnævnte og en af de førstnævnte tilhørte sammen kompagni, nemlig stabskompagniet ved hold 8 af den danske bataljon i U N CRO.

\section{Diskussion}

Pilotstudiet har vist, at der i perioden 1995 til 1997, begge år inklusive, er begået i alt 4 selvmord blandt soldater udsendt i international tjeneste. I midlertid forekommer 3 af de 4 selvmord blandt personellet fra én bestemt underafdeling på i alt 370 mand. I soleret betragtet opnår denne enhed derfor et relativt højt antal selvmord, som er langt højere end det forventede. Det er interessant at pilotstudiet således ikke kan bekræfte en delkonklusion fra spørgeskemaundersøgelsen af hold 7 og 8 fra det danske bidrag til U N CRO, hvor det hedder "at ST KM P/hold 8 udvikler færre reaktioner end både øvrige kompagnier fra hold 8 og B-K M P/hold7" (A ndersen 1998). $0 \mathrm{~m}$ end nærværen de undersøgelse ikke direkte kan påvise en sammenhæng mellem oplevelserne under international tjen este og evt. efterføl gen de selvmord, kan der dog ikke herske tvivl om at dette kompagni var udsat for en hård belastning allerede ved ankomsten til et område, hvor der havde været betydelige kampe, der også havde medført tab af danske soldater samt en del tilskadekomne. O pgaven synes således med ét ændret, og der var usikkerhed om fremtiden for enheden. Y derligere blev enheden i denne periode involveret i nye voldsomme kamphandlinger, som bl.a. i alt medførte tab af 2 danske soldater og 16 sårede. 


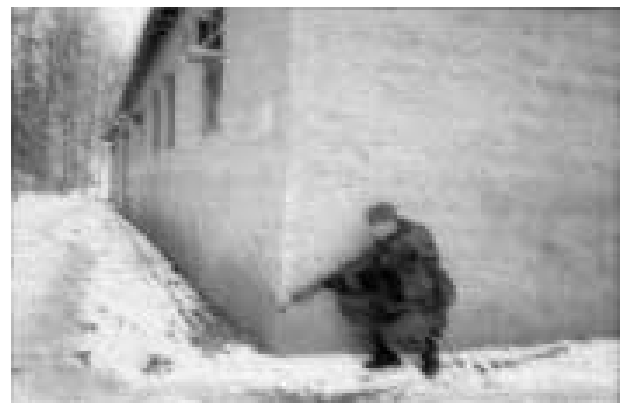

Enheden begyndte efterfølgende at gå i opløsning med deraf ledel sesmæssige følger. 0 mtrent en måned efter de ulykkelige begivenheder opløstes og splittedes enheden efter en kort afviklingsfase hjemme.

I undersøgelsen indgår også de 2 sel vmord, der blev begået inden udsendelse. Begge var, da sel vmordene skete umiddelbart inden udsendelsen, enkadreret i de enheder, som skulle sendes ud. Det kan derfor ikke udelukkes, at årsagerne til disse selvmord kan have været tjenstligt relateret. Den ene af de to havde tidligere været udsendt, hvilket også kan have haft en visindflydelse.

På det givne tidspunkt var forsvarets beredskab stadig under udvikling i forhold til det i dag gældende opfølgningsprogram. Dette har indtil for nylig været begrænset til oplysning om muligheden for behandling ved hjemsen delse samt intervention hos repatrierede, men omfatter nu også en spørgeskemaundersøgelse, der tilsigter en samlet opfølgning af hele enheden (A ndersen 1998).

D et danske forsvar har nu formuleret en politik ( $M$ artini 1997) vedrørende den psykiske trivsel hos tjenestegørende personel - både under tjeneste og efter hjemsendelse. I formuleringen udelukkesikke, at personel, der forretter udenlandstjeneste, kan få oplevel ser, som sætter sig spor hos personen, men sætter grænsen ved "efterreaktioner, som i væsentlig grad påvirker deres hverdag". For at kunne vurdere hvorvidt denne politik egentlig efterleves, kræves der derfor en viden, som både i omfang og tid kan siges at være dækkende for det udsendte personel. De foretagne spørgeskemaundersøgel ser har haft en svarprocent mellem 50\% og 75\%, hvilket efterlader en endog betydel ig restgruppe, hvorom der ikke eksisterer konkret viden. PT SD (Post Traumatic Stress Disorder) udgør her en særlig udfordring, idet syndromet også kan optræde med en betydelig latenstid i forhold til tidspunktet for den traumatiserende oplevelse. PT SD er også forbundet med en øget risiko for selvmord og sel vdestruktiv adfærd (Bullman \& Kang 1994).
Resultaterne af pilotundersøgelsen skal vurderes i forhold til metoden. Som observationstid er der val gt et år efter hjemsendelse. Dette er i overen sstemmelse med den metode som generelt væl ges ved registerundersøgel ser, idet en længere observationstid ville gøre en kausal sammenhæn mellem udsen del se og evt. selvmord mindre valid. Imidlertid er der $\mathrm{i}$ andre undersøgel ser fundet belæg for, at psykiske eftervirkninger, herunder selvmordstanker og gennemført selvmord, kan optræde op til flere år efter en given traumatiserende oplevelse (Bullman \& Kang 1994).

Endvidere er det talmæssige grundlag for undersøgelsen (en kohorte på 3.859 mand med 4 selvmord) for spinkelt til i statistisk henseende at kunne drage sikre konklusioner. G enerelt må det dog siges, at resultaterne ligger på linie med fx norske undersøgelser, hvor man har opgjort erfaringerne fra U N IFIL (FN -styrken til overvågelse af grænsen mellem Libanon og Israel) (Thoresen et al. 2002).

Danmark, og andre lande, som bidrager til internationale fredsbevarende styrker, kan formentlig i mange år fremover forudse udsendelse af et betydeligt antal soldater. Senest vil krigen i I rak også betyde et engagement, og D anmark har således også udsendt et antal soldater til dette område fra juni måned 2003. I øjeblikket udsendes der fra Danmark omkring 2000 soldater per år. Derfor vil fortsat opfølgning af og forskning i soldaternes mentale velbefindende være relevant og nødvendig. På baggrund af pilotstudiet er det forfatternes opfattelse, at betydelig viden vil kunne opnås gennem en udvidet retrospektiv registerundersøgel se af dødeligheden blandt militært personel, der har været udsendt i international tjen este. Det er vigtigt at udvide kohortensstørrelse, men det er ligeså vigtigt at udvide observationstiden mellem hjemsen delse og eventuel suicidal adfærd. Sidstnævnte fordrer dog en nærmere undersøgelse af hvert enkelt dødsfald for at afklare mulig kausal sammenhæng med missionsudsen delse. Ligeledes vil det være af værdi at udvide fremtidige undersøgelser til også at omfatte psykiatrisk morbiditet. I sig selv har dette interesse, men det vil også øge den statistiske validitet af gjorte observationer.

Fuldstæn dig referenceliste : se nedenfor.

\section{Referencer}

A ndersen HE. D anske FN -soldater 2 år efter. 0 pfølgningsundersøgelse af D A N B AT hold 7 og 8. FC LPU B (144). København: Forsvarets Center for Lederskab, 1998

Bullman TA, Kang HK. Posttraumatic stress disorder and the risk of traumatic deaths among Vietnam veterans. J N erv M ent Dis 1994, 182:604610.

H ansen-Schwartz J, Jessen $G$, A ndersen $K$, Jørgensen $\mathrm{HO}$. Selvmordsadfærd blandt soldater udsendt til international tjeneste. Et pilotprojekt omhandlende 1995-1997. København: Forsvarets Sanitetsskole, 2001.

H ansen-Schwartz J, Jessen G, A ndersen K, Jørgensen $\mathrm{HO}$. Suicide after deployment in $\mathbf{U} \mathbf{N}$ peacekeeping missions - $a \mathrm{D}$ anish pilot study. Crisis 2002, 23(2): 55-58.

Jessen $G, H$ ansen-Schwartz J, A ndersen $K$, |ørgensen $\mathrm{HO}$. Suicidal risk after $\mathrm{U} \mathbf{N}$ peace-keeping missions. Preliminary $D$ anish Experiences.

8th European Symposium on suicide and suicidal behaviour, Bled, 2000.

$M$ artini, S. Soldat i fredens tjeneste - mødet med "krigens gru". Dan ske erfaringer med forebyggelse og behandling. FCL brev, 1997.

Thoresen S, M ehlum L. Selvmordsforebygging også i FN -styrkerne? N ytt i Suicidologi 1998, 3 : 11-13.

Thoresen S, M ehlum L, M øller B. Suicide in Peacekeepers: A $n$ Epidemiological Study of Suicide in 22,275 Veterans from N orwegian Peacekeeping 0 perations. Prehosp Disast M ed 2002, 17(1).

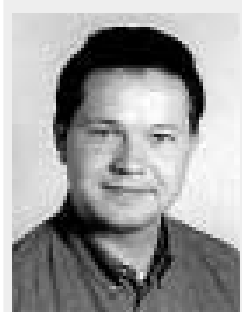

Jacob $\mathrm{H}$ ansen-Schwartz er dr.med og ansat ved neurokirurgisk afdeling ved $\mathrm{A}$ alborg U niversitetshospital. $\mathrm{H}$ an har gjort tjeneste som militærlæge siden 1993 og har også været udsendt til de danske bataljoner $\mathrm{i}$ Bosnien og Kosovo.

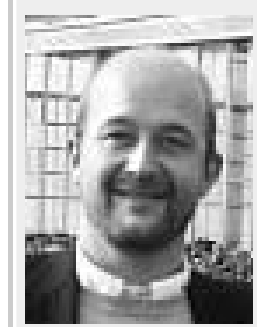

G ert Jessen, M A , Erhvervs DiplomL eder, har nationalt og internationalt arbejdet med suicidologi som forsker og underviser gennem 15 år. $\mathrm{H}$ an har i mange år vært tilknyttet C enter for selvmordsforskning i O dense. $\mathrm{H}$ an er nu dels selvstændig og dels chef-konsulent indenfor $\mathrm{H}$ uman Ressources $\mathrm{i}$ et privat firma.

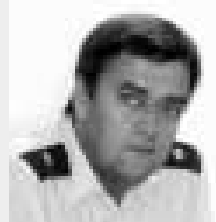

$\mathrm{H}$ ans $\mathrm{Ole}$ Jørgensen har siden 1991 været læge i det danske Forsvar og er stabslæge ved Danske Division. I flere omgange har han været ledende læge ved de danske Batal joner udstationeret i Kroatien og Bosnien. 


\section{Fuldstændig referenceliste}

Aarhaug P, Weisæth L, Mehlum L, Larsen L. The UNIFIL-study 1991-1992. Results and recommendations. Oslo: The Joint Medical Service, HQ Defence Command, Norway, 1993.

Andersen HE. Danske FN-soldater 2 år efter. Opfølgningsundersøgelse af DANBAT hold 7 og 8. FCLPUB (144). Copenhagen: Forsvarets center for lederskab, 1998.

Bille-Brahe U, Jessen G. Suicide in Denmark, 1922-1991: the choice of method. Acta Psychiatrica Scandinavica 1994; 90:91-96.

Brooking JI. Potential psychological problems of army medicine services personnel in combat with particular reference to the Territorial Army. Journal of the Royal Army Medical Corps 1983; 129:146-153.

Bullman TA, Kang HK. Posttraumatic stress disorder and the risk of traumatic death among Vietnam veterans. Journal of Nervous and Mental Disease 1994; 182:604-610.

Campion EW. Disease and suspicion after the Persian Gulf War. New England Journal of Medicine 1996; 335:15251527.

Davidson JR, Hughes D, Blazer DG, George LK. Post-traumatic stress disorder in the community: an epidemiological study. Psychological Medicine 1991; 21:713-721.

Fontana A, Rosenheck R. Attempted suicide among Vietnam veterans: a model of etiology in a community sample. American Journal of Psychiatry 1995; 152:102-109.

Goodale PA. Anger profile of suicidal inpatients Vietnam veterans. Dissertation Abstracts International 1999; 59:5577B.

Hansen-Schwartz J, Jessen G, Andersen K, Jørgensen HO. Selvmordsadfærd blandt soldater udsendt til international tjeneste. Et pilotprojekt omhandlende 1995-1997. Copenhagen: Forsvarets Sanitetsskole, 2001.

Hendin H, Haas AP. Suicide and guilt as manifestations of PTSD in Vietnam combat veterans. American Journal of Psychiatry 1991; 148:586-591.

Hytten K, Weisæth L. Suicides among soldiers and young men in the Nordic countries 1977-1984. Acta Psychiatrica Scandinavica 1989; 79:224-228.

Kang HK, Bullman TA. Mortality among U.S. veterans of the Persian Gulf War. New England Journal of Medicine 1996; 335:1498-1504.

Kettner B. Combat strain and subsequent mental health. A follow-up study of Swedish soldiers serving in the UN-forces 1961-62. Acta Psychiatrica Scandinavica Supplementum 1972; 230:1-112.

Kramer TL, Lindy JD, Green BL, Grace MC, Leonard AC. The comorbidity of post-traumatic stress disorder and suicidality in Vietnam veterans. Suicide and life-Threatening Behaviour 1994; 24:58-67.

Litz BT, Orsillo SM, Friedman M, Ehlich P, Batres A. Posttraumatic stress disorder associated with peacekeeping duty in Somalia for U.S. military personnel. American Journal of Psychiatry 1997; 154:178-184.

Mehlum L. Positive and negative consequences of serving in a UN peacekeeping mission. A follow-up study. International Review of the Armed Forces Medical Service 1995; 58:289-295.

Mehlum L. Suicidal ideation and sense of cohorence in male conscripts. Acta Psychiatrica Scandinavica 1998; 98:487492.

Mehlum L. Forebygging av selvmord blant militært personell. In L Mehlum (Ed), Tilbake til livet (pp. 288-302). Oslo: HøyskoleForlaget, 1999. 
Paykel ES, Prusoff BA, Myers JK. Suicide attempts and recent life events. Archives of General Psychiatry 1975; 32:327-333.

Powell KE, Fingerhut LA, Branche CM, Perrotta DM. Deaths due to injuries in the military. American Journal of Preventive Medicine 2000; 18(3S):26-32.

Thoresen S, Mehlum L. Selvmordsforebygging - også I FN-styrkerne? Nytt i Suicidologi 1998; 3: 11-13.

Ward W. Psychiatric morbidity in Australian veterans of the United Nations peacekeeping force in Somalia. Australian and New Zealand Journal of Psychiatry 1997; 31:184-193.

Weisæth L. Stress of UN military peacekeeping. Wismic Newsletter 1990; 2:15-18.

World Health Organisation. The ICD-10 classification of mental and behavioural disorders. Clinical descriptions and diagnostic guidelines. Geneva, 1992. 